\title{
Supercritical Fluid Fractionation Process Development: A Techno-economic Analysis of Retrofitting an Aroma Production Process
}

\author{
S.C. Hendricks, T.F.N. Madzimbamuto, and T.V. Ojumu
}

\begin{abstract}
Consumer preference has swung away from synthetically produced aroma compounds in favour of natural ones. Apple aroma is produced as one of the by-products during the evaporation stage in the production of fruit sugars. This process results in a highly diluted product containing a high fraction of non-aroma organic components such as hexanol. This research is a techno-economic analysis to test the effectiveness of replacing a traditional flavour extraction unit to concentrate apple aroma with one based on supercritical $\mathrm{CO}_{2}$ fractionation. A process model developed based on the traditional evaporation process route were validated using industrial product samples, and for the suggested process, it is based on flash calculations, which is validated using pilot plant data. Several retrofitted scenarios are suggested and compared based on energy utilization. Initial results indicate that appending the existing process with a counter-current $\mathrm{scCO}_{2}$ column can achieve high-value aroma concentrates, and requires least capital outlay.
\end{abstract}

Keywords-Apple Aroma, Countercurrent fractionation, Supercritical $\mathrm{CO}_{2}$, Feasibility, Retrofitting, Process Modelling.

\section{INTRODUCTION}

South Africa is known for producing a large variety of fruit, especially in the Ceres and Groenland regions of the Western Cape. Apples constitute the bulk of the fruit produced there, both for domestic and international markets[1]. They are processed into products such as apple juice, dried apples and cider[2]. Less known is the fact that a large portion of the annual crop is processed into sugars, such as fructose and sucrose. The process route is, however, well established[3]. During this process, apple aroma is produced as one of the by-products, specifically at the concentration stage, where the bulk of the water in the fruit juice is removed[2]. Since evaporation is used at this stage, the process has a number of drawbacks[4]. Thermal processes tend to be expensive, particularly where the boiling of water is involved. In addition, thermally labile compounds that comprise many flavours tend to degrade[5]. Further, the flavour fraction that is obtained during evaporation tends to be much diluted in water[6]. The risk of retaining residual solvent in the product rules out the use of solvent extraction in modern processes, due to adverse consumer preference for this method of production, in addition, to the growing unacceptability of the environmental impact of such processes[3].

Selective extraction with $\mathrm{CO}_{2}$, however, may overcome all of the drawbacks discussed above. $\mathrm{CO}_{2}$ is "generally regarded

S.C. Hendricks, T.F.N. Madzimbamuto, and T.V. Ojumu, Department of Chemical Engineering, Cape Peninsula University of Technology, Bellville 7535, Cape Town, South Africa. as safe" (GRAS) for use during the processing of food products, as it is benign [7, 8]. In its supercritical state, $\mathrm{CO}_{2}$ performs best at temperatures just above its critical parameters, i.e. $31^{\circ} \mathrm{C}$ and 74 atmospheres [9], where its density is highest. These conditions are equally benign with regard to the fragility thermally labile of the process on the environment is virtually negligible, as the process does not itself produce $\mathrm{CO}_{2}$ [8]. No boiling of water is involved, and the solvent is continuously recycled, thus the costs of processing are low[10].

Literature reveals that the use of SFE using $\mathrm{CO}_{2}$ can be feasible for the concentration of aroma compounds in essential oils, for the fractionation of fish and vegetable oils to concentrate the tocopherols, esters and other non-saponifiable compounds found in animal and vegetable oils[8]. The economic viability of concentrating apple aroma has, however, not been demonstrated.

In this study two methods of concentrating apple aroma was investigated; one traditional method that is currently used in the South African industry (evaporation) and one method not commonly known in industry (supercritical fluid extraction). These two methods will be compared based on the quality of the high concentrated apple aroma extract and feasibility. A retrofit will also be developed to replace the current traditional methods with supercritical fluid extraction in order to produce a product of better quality that will fetch a higher value on the market. This research is aimed at the investigation of the technical feasibility and economic viability of an alternative processing method for the production of apple aroma from the fruit juice, using $\mathrm{CO}_{2}$ as a selective solvent to concentrate the key apple aroma components.

A study done by Bejarano \& del Valle (2017) shows that key apple aroma components can be extracted at maximum operating conditions of $40{ }^{\circ} \mathrm{C}, 14 \mathrm{MPa}$ and $\mathrm{S} / \mathrm{F}=5[11]$. The authors prepared a model solution that comprised of hexanal, (E)-2-hexenal and hexanol and the effect of temperature, pressure and solvent-to-feed ratio was studied on the concentration of the model solution[11].

A Gas Chromatography (GC) analysis of apple aroma obtained from Elgin Fruit Juices shows that the key components (hexanal and (E)-2-hexenal) are not in significant amounts in apple aroma however these components contributes mainly to the characteristic scent of the aroma[12].

In this present study, experimental work was performed on an apple aroma sample obtained from Elgin Fruit Juices (Pty) Ltd as well as a model solution. Preliminary results show that key apple aroma components are extractable from a diluted solution by using supercritical $\mathrm{CO}_{2}$. However, perfect separation of the key apple aroma components (for example the 
esters and aldehydes) from the non-key components such as the alcohols have not been achieved.

\section{MATERIALS AND METHODS}

\section{A. Materials}

Food grade carbon dioxide $(99,99 \%$ purity) supplied by Air Liquid. Industrial apple aroma solution supplied by Elgin Fruit Juices (Pty) Ltd. Model apple aroma solution of water (distilled), hexanol, butanol, trans-2-hexenal, ethylbutanoate and hexanal.

\section{B. Experimental apparatus and method}

The experiment was performed using the process as shown in figure 1 and the equipment was purchased from Separex. The conditions for the operation of the column (I) were selected based on literature data and the column was run in batch mode.

Pure $\mathrm{CO}_{2}$ (99.99\% purity), in its vapour form, was fed to the system (from figure 1). This line is connected to a recycle stream (controlled by a manual valve MV100) from the separation vessels (VII-X), which also contains pure $\mathrm{CO}_{2}$. This valve is usually flared to the atmosphere before the start-up of the plant, to avoid any impurities entering the feed stream. Once the plant start-up has commenced, the valve was turned to the open position. The $\mathrm{CO}_{2}$ from the feed stream entered through the cooler (I), which cools the $\mathrm{CO}_{2}$ down to below $283.15^{\circ} \mathrm{K}$. This ensures that the $\mathrm{CO}_{2}$ is in its liquid form when passing through the piston pump (II). The $\mathrm{CO}_{2}$ flow rate is controlled by the pump and the pump ensures flow through the system as well. The $\mathrm{CO}_{2}$ is then pumped through a heat exchanger (III) which then heats it up to a temperature above its critical temperature, usually above $304.15^{\circ} \mathrm{K}$, to ensure that it is in its supercritical state before entering the column. The $\mathrm{CO}_{2}$ vapour enters the bottom of the column (V) operating at $>71$ $\mathrm{MPa}$ (the critical pressure of $\mathrm{CO}_{2}$ ) and at a set point temperature of $\sim 313.15^{\circ} \mathrm{K}$. The pressure is maintained by an automatic valve ARV400 and the temperature is controlled by the heating jackets surrounding the column. The pressure and temperature are controlled and monitored by a computer program (Lab View). The column is a randomly packed column with pole rings and has a height of $4 \mathrm{~m}$ and a diameter of $28 \mathrm{~mm}$.

$600 \mathrm{ml}$ of the apple aroma was fed through the piston pump (IV) at stage 3 of the column (V) through MV423. The $\mathrm{CO}_{2}$ then passed through the apple aroma in the column at a rate of $10 \mathrm{~kg} / \mathrm{hr}$ and this left through the top of the column through AR400, however

The compound is separated from the $\mathrm{CO}_{2}$ in the separation vessels operating at a pressure of $\sim 5000 \mathrm{kPa}$. The decrease in pressure makes $\mathrm{CO}_{2}$ less dense and consequently decreases the solvent power, which will then make it easier to separate the aromatic compounds from the $\mathrm{CO}_{2}$. The $\mathrm{CO}_{2}$ is then recycled back to the process.

Sampling was done as follow. Raffinate* was collected every 5 minutes (thrice) with 30 minute intervals. At the end of run the column was emptied (raffinate) and samples of the separators (the extract) were collected.

The operating conditions for the preliminary experiment were set as follow. $40^{\circ} \mathrm{C}$ and $14 \mathrm{MPa}, 40^{\circ} \mathrm{C}$ and $17 \mathrm{MPa}$, and $50^{\circ} \mathrm{C}$ and $17 \mathrm{MPa}$. For this experimental work the operating condition were set between $40-80^{\circ} \mathrm{C}, 80-150 \mathrm{MPa}$ and $\mathrm{S} / \mathrm{F}$ of 5-15 for continuous process and for batch a $\mathrm{CO}_{2}$ flowrate of $5-10 \mathrm{~kg} / \mathrm{hr}$ was selected.

*Collected at the bottom of the column

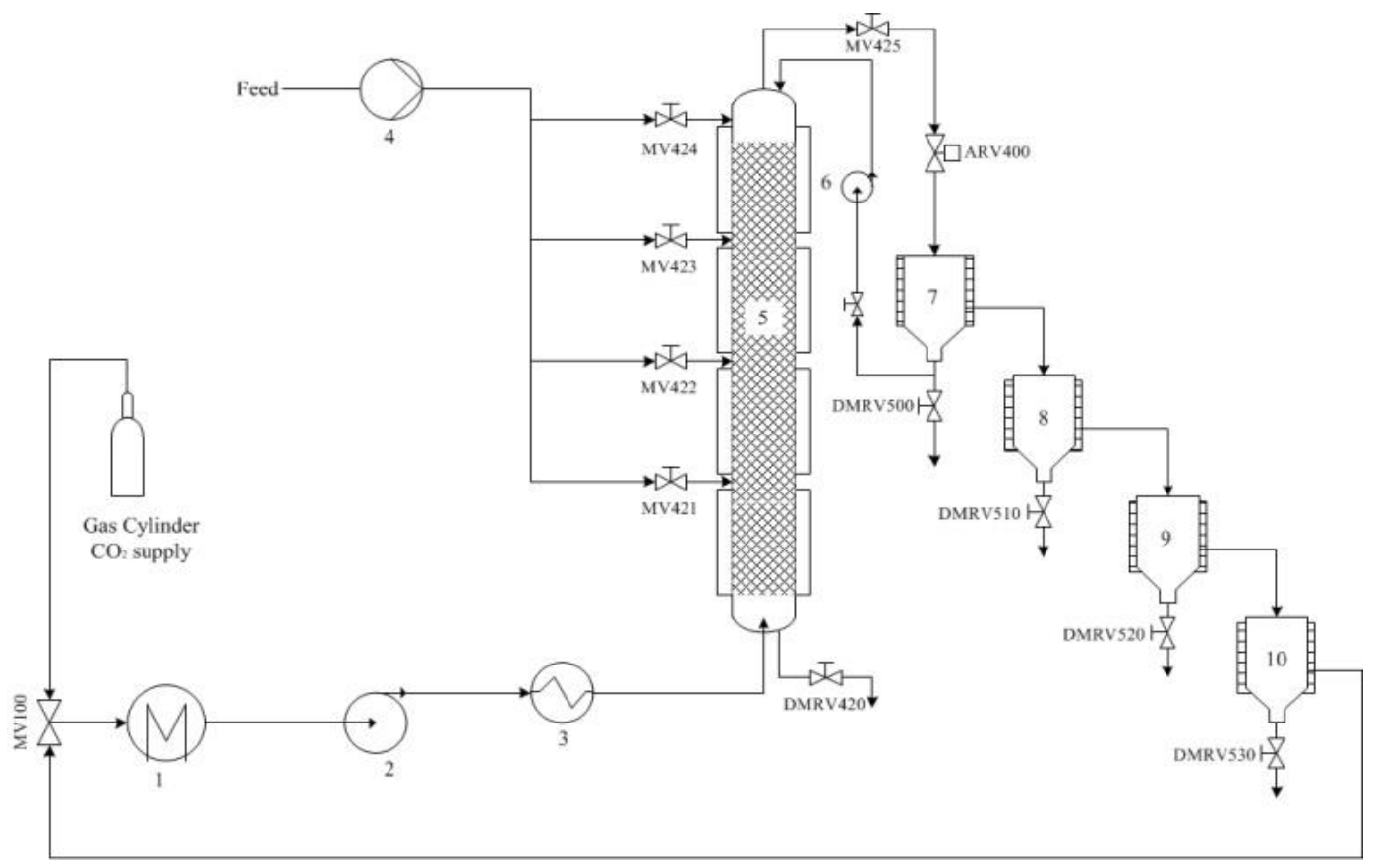

Fig. 1: Schematic Diagram of Fractionation Column. (I) Chiller, (II) $\mathrm{CO}_{2}$ supply pump, (III) Heater, (IV) Feed pump, (V) Fractionation Column, (VI) Reflux pump, (VII-IX) Separation vessels, (X) Liquid filter. 


\section{REFERENCES}

[1] HortGro, "KEY DECIDUOUS FRUIT STATISTICS 2017," 2017.

[2] W. H. Root and D. M. Barrett, "Apples and Apple Processing," in Processing Fruits: Science and Technology, 2nd ed., Boca Raton: CRC Press, 2005, pp. 455-480. https://doi.org/10.1201/9781420040074.pt2

[3] J. Börjesson, H. O. E. Karlsson, and G. Trägårdh, "Pervaporation of a model apple juice aroma solution: comparison of membrane performance," J. Memb. Sci., vol. 119, pp. 229-239, 1996. https://doi.org/10.1016/0376-7388(96)00123-8

[4] D. Barrett, L. Somogyi, and H. Ramaswamy, Processing Fruits Science and Technology Second Edition, 2nd ed. Boca Raton: CRC Press, 2005. https://doi.org/10.1201/9781420040074

[5] S. Saffarionpour and M. Ottens, "Recent Advances in Techniques for Flavor Recovery in Liquid Food Processing," Food Eng. Rev., vol. 10, no. 2, pp. 81-94, 2018. https://doi.org/10.1007/s12393-017-9172-8

[6] R.-D. Rita, K. Zanda, K. Daina, and S. Dalija, "Composition of aroma compounds in fermented apple juice: effect of apple variety, fermentation temperature and inoculated yeast concentration," Procedia Food Sci., vol. 1, pp. 1709-1716, 2012.

https://doi.org/10.1016/j.profoo.2011.09.252

[7] M. Mukhopadhyay, Natural Extracts using Supercritical Carbon Dioxide. Boca Raton: CRC Press, 2000. https://doi.org/10.1201/9781420041699

[8] E. Reverchon and I. De Marco, "Supercritical fluid extraction and fractionation of natural matter," J. Supercrit. Fluids, vol. 38, no. 2, pp. 146-166, 2006. https://doi.org/10.1016/j.supflu.2006.03.020

[9] E. Reverchon, "Supercritical fluid extraction and fractionation of essential oils and related products," J. Supercrit. Fluids, vol. 10, no. 1, pp. 1-37, 1997. https://doi.org/10.1016/S0896-8446(97)00014-4

[10] G. Brunner, "Counter-current separations," J. Supercrit. Fluids, vol. 47, no. 3, pp. 574-582, 2009 https://doi.org/10.1016/j.supflu.2008.09.022

[11] A. Bejarano and J. M. del Valle, "Countercurrent fractionation of aqueous apple aroma constituents using supercritical carbon dioxide," J. Supercrit. Fluids, vol. 120, pp. 266-274, 2017. https://doi.org/10.1016/j.supflu.2016.08.001

[12] D. R. Sepulveda, A. C. Development, A. C. Development, G. I. Olivas, and A. C. Development, "Biochemistry of Apple Aroma : A Review," no. October, 2016. 